\title{
Effect of Nozzle Orifice Geometry on Spray, Combustion, and Emission Characteristics under Diesel Engine Conditions
}

\author{
Sibendu Som ${ }^{\mathrm{a}} *$, Suresh K Aggarwal ${ }^{\mathrm{b}}$ \\ aArgonne National Laboratory, Argonne, IL-60439, USA \\ ${ }^{\mathrm{b}}$ University of Illinois at Chicago, Chicago, IL-60607, USA
}

Corresponding Author: Sibendu Som

Argonne National Laboratory

Energy Systems Division

9700 S. Cass Avenue

Argonne, IL-60439, USA

Phone: (630)252-5273

Fax: (630)252-3443

Email: ssom@anl.gov 


\section{ABSTRACT}

Diesel engine performance and emissions are strongly coupled with fuel atomization and spray processes, which in turn are strongly influenced by injector flow dynamics. Modern engines employ micro-orifices with different orifice designs. It is critical to characterize the effects of various designs on engine performance and emissions. In this study, a recently developed primary breakup model (KH-ACT), which accounts for the effects of cavitation and turbulence generated inside the injector nozzle is incorporated into a CFD software CONVERGE for comprehensive engine simulations. The effects of orifice geometry on inner nozzle flow, spray, and combustion processes are examined by coupling the injector flow and spray simulations. Results indicate that conicity and hydrogrinding reduce cavitation and turbulence inside the nozzle orifice, which slows down primary breakup, increasing spray penetration, and reducing dispersion. Consequently, with conical and hydroground nozzles, the vaporization rate and fuel air mixing are reduced, and ignition occurs further downstream. The flame liftoff lengths are the highest and lowest for the hydroground and conical nozzles, respectively. This can be related to the rate of fuel injection, which is higher for the hydroground nozzle, leading to richer mixtures and lower flame base speeds. A modified flame index is employed to resolve the flame structure, which indicates a dual combustion mode. For the conical nozzle, the relative role of rich premixed combustion is enhanced and that of diffusion combustion reduced compared to the other two nozzles. In contrast, for the hydroground nozzle, the role of rich premixed combustion is reduced and that of non-premixed combustion is enhanced. Consequently, the amount of soot produced is the highest for the conical nozzle, while the amount of NOx produced is the highest for the hydroground nozzle, indicating the classical tradeoff between them. For all three nozzles, flame stabilization seems to occur through a flame propagation mechanism, rather than an ignition kernel based mechanism. The flame structure and stabilization are also influenced by orifice geometry.

Keywords: Diesel engine, nozzle geometry, flame liftoff, NOx and soot emissions, detailed chemistry, primary breakup, atomization, ignition delay 


\section{INTRODUCTION}

Diesel engine performance and emission characteristics are largely determined by fuel atomization and spray processes, which in turn are strongly influenced by injector flow dynamics. Modern diesel engines employ micro-orifices with different orifice designs, and it is critical to characterize the effects of various designs on engine performance and emissions. The flow inside the injector is controlled by dynamic factors (injection pressure, needle lift, etc.) and geometrical factors (orifice conicity, hydrogrinding, etc.). The effects of dynamic factors on the injector flow, spray combustion, and emissions have been investigated by various researchers including $[1,2,3,4]$. There have also been experimental studies concerning the effects of nozzle orifice geometry on global injection and spray behavior $[5,6,7,8,9,10,11,12,13]$.

Benajes et al. [9] conducted an experimental study to analyze the influence of conical and cylindrical nozzle orifices on injection rate behavior of a common-rail fuel injection system at maximum needle lift under steady state conditions in a cavitation test rig. They observed that compared to a cylindrical orifice a conical orifice reduces cavitation, increases flow efficiency (discharge coefficient) and exit velocity, although the fuel injection rate is reduced due to the smaller exit area. Payri et al. [10] observed choking conditions with cylindrical nozzles whereas for conical nozzles the mass flow rate was always proportional to the square root of pressure drop indicating absence of cavitation at the nozzle exit. They also observed an increase in injection velocity due to the presence of vapor at orifice exit for the cylindrical nozzle. Han et al. [11] compared conical and cylindrical nozzles and found that the primary breakup region is strongly influenced by nozzle geometry. The effect of orifice geometry on spray penetration, liquid length, and cone angle has also been examined. Payri et al. [5] and Blessing et al. [8] reported that for non-evaporating sprays the increase in conicity results in greater liquid penetration and smaller cone angle. However, Bae et al. [7] found that spray tip penetration and cone angle decreased due to increase in conicity which is in direct contradiction to studies by Payri et al. and Blessing et al. Simulations by Som et al. [14] provided further insights on this issue and confirmed that conicity suppresses cavitation and turbulence inside the nozzle, which are known to enhance primary breakup. Consequently, with a conical, the breakup process becomes slower, producing larger droplets and increased liquid penetration. Payri et al. also studied the spray penetration and liquid length under evaporating conditions for various nozzle geometries [6]. 
The literature review indicates that while the effect of orifice geometry on the injector flow and spray processes has been examined to some extent, its influence on engine combustion and emissions is not well established. To the best of our knowledge, the influence of nozzle geometry on spray and combustion characteristics has also not been studied numerically, mainly due to the complicated nature of flow processes associated. These form the major motivation for the present study i.e., to examine the effects of nozzle orifice geometry on inner nozzle flow, non-evaporating, evaporating, and combusting sprays, emission characteristics under diesel engine conditions. With increasingly stricter emission regulations and greater demand on fuel economy, the injector perhaps has become the most critical component of modern diesel engines. Consequently, it is important to characterize the effects of orifice geometry on injection, atomization and combustion behavior, especially as the orifice size keeps getting smaller and the injection pressure higher. In order to achieve the proposed objectives, we first examine the effects of orifice geometry on the injector flow, including the cavitation and turbulence generated inside the nozzle. We then couple the injector flow simulations with engine simulations, and investigate the effects of hydrogrinding and conicity on the non-evaporating and evaporating spray behavior. Qualitative comparisons with available data in literature $[5,8]$ are also performed.

Diesel engine combustion is characterized by a dual burning mode involving a rich premixed flame and a diffusion flame. Most of the soot and unburned hydrocarbons are generated in the rich premixed flame, while NOx production mainly occurs in the nonpremixed flame. Consequently, engine emissions are determined by the relative contributions of the rich premixed and diffusion flames [15], which in turn depend upon conditions in the flame stabilization region. An important consideration in this context is the flame stabilization location or liftoff length $[16,17,18]$, which strongly depends on fuel-air mixing and ignition behavior upstream of the flame. Therefore, another objective of this study is to examine the effects of nozzle geometry on the flame liftoff length, structure, and stabilization. To the best of our knowledge, there are no studies establishing the influence of nozzle geometry on flame liftoff and stabilization characteristics. With regards to stabilization, we also examine if lifted flames under diesel engine conditions stabilize through a propagation mechanism [19], characterized by a balance between edge flame speed and local flow velocity along the stoichiometric contour, or through an ignition kernel that continuously provides radical species. For instance, Pickett et al. 
$[20,21]$ observed flame stabilization through the second mechanism for both auto-ignition and externally induced ignition conditions. Also, extensive validations of fuel oxidation chemistry and soot model will be presented.

\section{PHYSICAL AND NUMERICAL MODEL}

The effect of orifice geometry on the injector flow was examined by considering a fullproduction injector (cf. Fig. 1), which was previously used for x-ray measurements of atomizing spray at Argonne National Lab [22]. The injector has six cylindrical holes with diameter of $169 \mu \mathrm{m}$ at an included angle of $126^{\circ}$. To simulate Argonne's experiments, a single spray plume in a constant-volume chamber was considered. A cylindrical geometry of $50 \mathrm{~mm}$ in diameter and $200 \mathrm{~mm}$ in length was generated [14]. The effects of conicity and hydrogrinding were examined by simulating three different orifices; (1) a cylindrical orifice as used in Argonne experiments (base nozzle), (2) a conical orifice, and (3) a hydroground orifice. The orifice conicity is defined in terms of a K-factor $(\mathrm{K})$ as:

$$
K=\frac{\left(D_{\text {in }}-D_{\text {out }}\right)}{10} \mu m
$$

where $D_{\text {in }}$ and $D_{\text {out }}$ are inlet and outlet orifice diameters (cf. Fig. 1b). The amount of hydrogrinding is represented by the radius of curvature at nozzle inlet, normalized by the nozzle radius, i.e., r/R (cf. Fig. 1b). Thus the base nozzle has a cylindrical orifice with exit diameter of $169 \mu \mathrm{m}, \mathrm{K}=0$ and $\mathrm{r} / \mathrm{R}=0$, the conical orifice is represented by $\mathrm{D}_{\text {out }}=149 \mu \mathrm{m}, \mathrm{K}=2$ and $\mathrm{r} / \mathrm{R}=0$, and the hydroground orifice by $\mathrm{K}=0, \mathrm{r} / \mathrm{R}=0.014$ (cf. Table 1 ). The 3-D turbulent flow simulations for these nozzles were performed using the CFD software FLUENT v6.3. Details of the 2-phase models used in these simulations and the validation studies for predicting the flow and cavitation characteristics are reported in Refs. [2,3].

In order to mimic the combusting spray experiments performed at Sandia National Laboratory [20,21], spray was injected in a constant-volume combustion vessel under diesel engine conditions. Spray and combustion simulations were performed using a EulerianLagrangian approach in CFD engine software CONVERGE [23,24,25]. It incorporates state-ofthe-art models for spray injection, atomization, turbulence, droplet collision and coalescence, combustion, and emissions processes. Since details of these models can be found elsewhere $[2,24,25]$, only a brief description is provided here. 
A blob model is used to inject liquid droplets with diameter equal to an effective nozzle diameter calculated based on injector flow simulations. The number and frequency of parcels injected are specified based on the rate of injection (ROI) profile computed from injector flow simulations. Following injection, the liquid breakup is simulated using the recently developed KH-ACT (Kelvin Helmholtz-Aerodynamics Cavitation Turbulence) model for primary breakup, and KH-RT (Kelvin Helmholtz-Rayleigh Taylor) model for secondary breakup. Details of these models and the strategy for coupling the injector flow and spray simulations are provided in our previous studies $[2,14,26]$. As discussed in these studies, the KH-ACT model can accurately incorporate the effects of nozzle orifice geometry, especially the effects of cavitation and turbulence, on primary breakup, while the commonly used $\mathrm{KH}$ model only considers the aerodynamic breakup, caused by the growth of KH instabilities [27].

Details of the droplet dynamics and vaporization models, including the effects of turbulent dispersion, droplet distortion, collision and coalescence, are provided in Refs. [23,24]. For combusting sprays, a detailed kinetics model for n-heptane combustion is employed using the SAGE chemical kinetic solver $[23,24]$. The mechanism has been developed at Chalmers University [28], and consists of 42 species and 168 reactions for n-heptane combustion and NOx formation. It is coupled with gas phase calculations through a well-stirred reactor model.

CONVERGE uses an innovative modified cut-cell Cartesian method for grid generation $[23,24]$. The grid is generated internally to the code at runtime. The adaptive mesh resolution (AMR) technique enables local mesh refinement in regions of high temperature and species gradients. In order to match the spray chamber geometry used in combustion experiments at Sandia National Laboratories [16], a cube of $108 \mathrm{~mm}$ was generated. For all the cases the base grid size was fixed to $8 \mathrm{~mm}$. In order to resolve the flow near the injector, four levels of fixed grid embedding was employed such that the minimum grid size was $0.5 \mathrm{~mm}$. Apart from this region, it is difficult to determine a priori where a refined grid is desired. Hence, four levels of adaptive mesh refinement were employed such that the minimum grid size was $0.5 \mathrm{~mm}$.

\section{RESULTS AND DISCUSSION}

\section{VALIDATIONS}

Extensive validations for both the injector and combusting spray simulations have been reported in our previous studies $[2,3,12,14,26]$. Validations for the injector flow included matching the discharge coefficient and vapor fraction (cavitation) regions [3]. Combusting spray 
validations included matching the flame liftoff and liquid lengths with Sandia measurements for a range of conditions [2,26,29]. In addition, x-ray radiography measurements [22] for the base nozzle were used for validating the KH-ACT model $[2,12,14]$. Additional validations against flame liftoff data and the detailed kinetic model against ignition delay data [30] are presented here. In addition, the soot model used in this study is also validated against data from Sandia National Laboratories.

As mentioned earlier, in the current study n-heptane is used as a surrogate fuel for diesel fuel combustion. N-heptane is a fuel surrogate of choice since its cetane number $(\sim 56)$ is similar to that of conventional diesel fuel. N-heptane mechanism [28] is validated against some recent auto-ignition delay data from Gauthier et al. [30] for n-heptane/air mixtures. Figure 2 plots ignition delay time versus 1000/temperature for various pressure ranges and covering ignition delay times over two orders of magnitude. Simulations were performed using the well-stirred reactor model in CHEMKIN 3.7 [31,32]. Figure 2 shows model generating consistent trends with data. The kinetic model was able to capture the negative temperature coefficient (NTC) regime especially at high pressures wherein, ignition delay times increases with initial temperature. Since this kinetic model agreed well with experimental data, it is used further in this study to simulate the combustion processes.

Figure 3 compares flame lift-off location obtained from experiments of Siebers and Higgins [16] and calculated using $\mathrm{OH}$ molefraction and temperature contours. According to Peters [19] flame lift-off occurs at the flame stabilization location under near stoichiometric conditions. In experiments, $\mathrm{OH}$ chemiluminescence provides an excellent marker of the high heat release regions and thus of lift-off length. In simulations, two criteria for flame lift-off are analyzed. One based on temperature contours i.e., farthest upstream location of $\mathrm{T}=2200 \mathrm{~K}$ contour and second based on the most upstream location of $\mathrm{OH}$ molefraction contours. In simulations (cf. Figs. $3 \mathrm{~b}$ and $3 \mathrm{c}$ ), white solid lines indicate the flame lift-off location. The simulation was performed with the KH-ACT model under base conditions (cf. Table 2). The field of view in the axial and radial directions is $80 \mathrm{~mm}$ and $40 \mathrm{~mm}$ respectively. Flame lift-off length predicted by the $\mathrm{OH}$ molefraction contour is marginally higher $(23.1 \mathrm{~mm})$ than the experimental value, while that predicted by the temperature contour $(22.1 \mathrm{~mm})$ is in better agreement with the experimental data. Hence, the temperature criterion is used from here on to predict flame lift-off location. 
Figure 4 presents a comparison of the measured and computed flame images, obtained using KH-ACT model, at different injection pressures and orifice diameters. Figure 5 presents more quantitative comparisons. The effects of injection pressure and orifice diameter on the flame structure and stabilization are well captured by the simulations as shown in Fig. 4. The liftoff length was observed (cf. Fig. 5a) to increase with orifice diameter, a trend well captured by simulations. However, the lift-off length is slightly underpredicted by simulations. This trend can be explained by the fact that the fuel injection rate and hence the total mass injected increases with increase in orifice diameter. Thus to form a conducive fuel-air mixture for ignition, the amount of air to be entrained also increases thus increasing the flame lift-off length. The liquid length is seen to increase linearly with orifice diameter (cf. Fig. 5a). This is an important result since with a smaller orifice, smaller liquid length can be achieved thus decreasing the chances of piston and wall impingements. This behavior is also well captured by simulations. Under these ambient and upstream conditions the KH-ACT model predicts a crossover point at about 135 $\mu \mathrm{m}$. Perhaps a more important observation from Fig. 5a is that with decreasing orifice diameter beyond $135 \mu \mathrm{m}$ the interaction between fuel vaporization and combustion processes can be avoided. The effect of injection pressure on the lift-off and liquid lengths is shown in Fig. 5b. As the pressure drop (difference between injection and ambient gas pressure) across the orifice increases, the lift-off length also increases. According to Peters [19], the flame lift-off length varies linearly with injection velocity, and since injection velocity increases with injection pressure, the monotonic increase in lift-off length with injection pressure is expected. This trend is well captured by simulations, however, the lift-off length is marginally underpredicted. Liquid length remains nearly constant with injection pressure which is consistent with previous experimental findings [33].

Validation for the soot model is provided in Fig. 6, which compares the planar laserinduced incandescence (PLII) images of soot [34] with the predicted normalized soot mass fraction distributions. In order to match the experimental conditions used at Sandia, simulations were performed with an injection pressure of 1400bar, and ambient density and temperature of $14.8 \mathrm{~kg} / \mathrm{m}^{3}$ and $1000 \mathrm{~K}$, respectively (cf. Table 2). Other injector and ambient conditions are reported in $[2,12,16]$. Figure 6 shows the temporal evolution during a typical combustion event. The time after SOI for each image is shown on the left, and color scaling of the predicted normalized soot mass fraction on the right. There is reasonably good agreement between the 
predicted and measured soot distributions. The experimentally observed trend that soot generation occurs beyond the flame liftoff length is well captured by the simulations, and so is the flame liftoff length. There was also a good correspondence between the predicted $\mathrm{C}_{2} \mathrm{H}_{2}$ and measured soot distributions (not shown).

\section{NOZZLE FLOW MODELING}

First set of simulations focused on the effect of orifice geometry on injection and atomization behavior. Figure 7 compares the amount of cavitation (or vapor volume fraction contours) generated in the three nozzles. For these simulations, a three-dimensional $60^{\circ}$-sector mesh using 60,000 cells, with tetrahedral elements in the sac region and structured orthogonal grids in other regions, was generated. Details are provided in Refs. [2,3]. For all three nozzles, a $2-\mathrm{D}$ view (though the mid-plane) is shown. The vapor volume fraction varies from 0 (pure liquid) to 1 (pure vapor). There is significant amount of cavitation with vapor reaching the nozzle exit for the base nozzle compared to the other two nozzles. Hence, at the orifice exit, liquid fuel is injected in the case of the conical and hydroground nozzles as against a mixture of fuel and vapor for the base nozzle, thus causing a decrease in density also.

Figure 8 presents injection velocity and discharge coefficient $\left(\mathrm{C}_{\mathrm{d}}\right)$ at nozzle exit for different pressure drops across the orifice. The back pressure was always fixed at 30bar hence, the change in injection pressure resulted in change in pressure drop across the orifice. With increase in injection pressure, injection velocity at the orifice exit is seen to increase which is expected. It should be noted that the injection velocity reported is an average value across the orifice exit. The average injection velocity and discharge coefficient are lowest for the base nozzle owing to the presence of cavitation at the orifice exit. Compared to the conical nozzle, the hydroground nozzle predicts higher injection velocities and $\mathrm{C}_{\mathrm{d}}$ hence, implying the fact that hydrogrinding is more efficient in improving flow efficiency compared to changing the conicity. The influence of nozzle geometry on mass flow rate and turbulence levels at the nozzle orifice exit is investigated next since these parameters are directly input in spray simulations as rate profiles for cavitation, turbulence, and fuel mass injected [14].

The turbulence levels in terms of turbulent kinetic energy (TKE) and turbulence dissipation rate (TDR) were higher for the base nozzle (cf. Table 3). Additional simulations were performed for all three nozzles by varying the injector conditions [2], and the results are summarized Table 3, showing the global effects of orifice geometry on the nozzle flow and 
injection characteristics. Important observations are that compared to the base nozzle, the exit density, velocity, and discharge coefficient are higher for the conical and hydroground nozzles, and this can be attributed to the suppression of cavitation for these nozzles. The fuel injection rate is lower for the conical nozzle due to a smaller exit diameter, but higher for the hydroground nozzle due to higher flow efficiency for this nozzle. It is also important to note that the parameters listed in Table 3 form input for the spray and combustion modeling, and thus couple the injector and spray simulations.

In order to perform coupled inner nozzle flow and spray simulations, a rate of injection profile of the fuel injected in addition to the turbulence and cavitation levels at the nozzle exit are necessary. This forms the necessary boundary condition for the KH-ACT model. The rate of injection profile for the base nozzle was measured [3]. The change in exit velocity, area, and density due to change in nozzle orifice geometry was calculated (cf. Table 3 and Fig. 8). These changes were incorporated to the base nozzle ROI profile to obtain injection rates for the hydroground and conical orifices as shown in Fig. 9a. Based on inner nozzle flow simulations, increase in nozzle orifice conicity (from $\mathrm{K}_{\text {factor }}=0$ to $\mathrm{K}_{\text {factor }}=2$ ) and hydrogrinding (from $\mathrm{r} / \mathrm{R}=0$ to $\mathrm{r} / \mathrm{R}=0.014$ ) resulted in an increase in nozzle exit velocity (cf. Fig. 8) and density (cf. Fig. 7). The mass flow rate is the lowest for the conical nozzle. Although the exit velocity and density were higher for the conical nozzle, the decrease in exit area from $169 \mu \mathrm{m}$ to $149 \mu \mathrm{m}$ seems to be the dominating effect. Mass flow rate was highest for the hydroground nozzle which is expected since the exit velocity and density increased with hydrogrinding while the nozzle exit area was $169 \mu \mathrm{m}$ (cf. Table 1). These observation regarding mass flow rates are consistent with the findings of Benajes et al. [9].

Figure $9 \mathrm{~b}$ presents the cavitation and turbulence levels at the orifice exit at different needle lift positions. The peak needle lift of this injector was $0.275 \mathrm{~mm}$ which corresponds to full needle open position. Other needle positions simulated are: $0.05 \mathrm{~mm}, 0.1 \mathrm{~mm}, 0.15 \mathrm{~mm}$, and $0.2 \mathrm{~mm}$ open respectively. A general trend observed is that the TKE increased with needle lift position which is expected since the injection pressure also increased resulting in higher Reynolds numbers. The turbulence levels at the nozzle exit were lower with hydroground and conical nozzle owing to more flow uniformity. The area coefficient $\left(\mathrm{C}_{\mathrm{a}}\right)$ is representative of the cavitation intensity at the nozzle exit. For hydroground and conical nozzles there was no vapor 
present at the nozzle exit at all needle lift positions hence, $\mathrm{C}_{\mathrm{a}}$ is always 1 . The base nozzle on the other hand predicted significant amount of vapor at the nozzle exit, which results in $\mathrm{C}_{\mathrm{a}}=0.92$. NON-EVAPORATING SPRAY MODELING

In the previous section, the influence of nozzle orifice geometry on cavitation, flow, and turbulence levels were investigated. These formed boundary conditions for spray and combustion simulations. The effect of nozzle orifice geometry on the spray characteristics is depicted in Figure 10, in terms of liquid penetration as a function of time (cf. Fig. 10a), and transverse liquid projected density profiles at fixed axial locations (cf. Fig. 10b). The liquid penetration is lowest for the base nozzle, which can be attributed to the enhanced primary breakup caused by the cavitation and turbulence generated inside this nozzle. The enhanced breakup leads to smaller sauter mean diameter (not shown here), and thus lower penetration. The hydroground nozzle yields higher spray penetration compared to that for the conical nozzle, which is due to the higher fuel injection rate for the former, as discussed earlier (cf. Fig. 9). The projected density profiles exhibit a Gaussian distribution as the spray spreads in the transverse direction, consistent with the x-ray radiography data [22]. The peak of distribution is representative of liquid mass in the spray core, while the tail indicates the extent of spray dispersion. For all the three nozzles, spray dispersion increases while the peak projected density decreases with axial distance, as the spray spreads due to its interaction with ambient air. An important observation is that the peak projected density is smallest and the spray dispersion highest for the base nozzle compared to the hydroground and conical nozzles. This is due to the enhanced liquid breakup, which leads to smaller droplets and thus higher dispersion for the base nozzle. In summary, results indicate significant amount of cavitation and turbulence generated for the base nozzle. This leads to enhanced primary breakup, and consequently smaller droplets, smaller liquid penetration, and higher spray dispersion for this nozzle compared to the hydroground and conical nozzles. Smaller droplets and higher dispersion imply enhanced fuel-air mixing with important consequences for the flame structure and emissions, as discussed next.

\section{EVAPORATING AND COMBUSTING SPRAY MODELING}

In the absence of geometrical details for the nozzle orifice used at Sandia National Laboratory, empirical correlations were used to determine the TKE, TDR, and extent of cavitation, as done in our previous study [14]. Since the ROI is typically a top-hat profile, these values at peak needle-lift position were used for evaporating spray simulations. As shown in our 
previous study [14], with such an approach, liquid length and vapor penetration can be accurately captured. Figure 11 depicts the effect of orifice geometry on the spray and flame development. The spray development is indicated in terms of liquid penetration, and the flame development in terms temperature contours at different times. Due to axisymmetric nature of the spray and combustion processes, images are presented on a cut-plane through the center of the fuel jet. The field of view in both axial and radial directions is $108 \mathrm{~mm}$ for all images. The flame liftoff length is defined by the farthest upstream location of $\mathrm{T}=2200 \mathrm{~K}$ contour, while the liquid length is defined by the maximum penetration of liquid fuel, and established at a location where the fuel injection rate balances the fuel evaporation rate [35]. The initial spray and combustion processes appear to be similar for the three nozzles. As the fuel is injected and atomized, the liquid penetration increases with time, and reaches its maximum value or "liquid length" at about $0.5 \mathrm{~ms}$ (cf. Fig. 12) after SOI. Following atomization, the fuel vaporizes and entrains hot air leading to fuel air mixing and ignition, which occurs between 0.42 and $0.45 \mathrm{~ms}$ after SOI for the three nozzles with two fairly symmetrical flame kernels formed downstream of the spray tip. Subsequently, the flame develops in a fuel rich region, and the flame base is seen to move upstream with time and eventually stabilizes at about $1.2 \mathrm{~ms}$ after SOI (cf. Fig. 12) and at a location that is apparently determined by a balance between a turbulent flame speed and local flow velocity. Results from several simulations indicated that flame stabilization occurs through a flame propagation mechanism under the conditions investigated, rather than an ignition kernel based mechanism observed by Pickett et al. [21]. This issue however warrants further investigation. It should also be noted that these simulations were Reynolds Averaged Navier Stokes (RANS) based, where the averaged concentration of species and temperature may be too low for auto-ignition. Large Eddy Simulation (LES) methods which are more accurate than RANS methods can capture the instantaneous species and temperature profiles which can lead to more auto-ignition zones. However, LES methods are computationally more expensive hence are scarcely used for detailed spray and engine simulations.

The effects of orifice geometry on the spray and combustion characteristics are summarized in Fig. 12 and Table 4. Figure 12 plots the flame liftoff and liquid lengths vs. time after SOI for the three nozzles. Consistent with spray penetration trends discussed earlier (cf. Fig. 10a), the liquid length is shortest for the base nozzle, again due to faster liquid breakup and smaller droplets produced with this nozzle. This implies faster vaporization and fuel-air mixing, 
leading to earlier ignition for this nozzle. This is confirmed by the values in Table 4, which indicates that ignition occurs earlier and closer to the injector for the base nozzle compared to other two nozzles. The liftoff length, however, exhibits somewhat different trend for the three nozzles. It is smallest for the conical nozzle, and largest for the hydroground nozzle. This behavior is related to the amount of fuel injected, vaporization rate, and fuel-air mixing for the three nozzles. Since the rate of fuel injection and total amount of fuel injected are highest for the hydroground nozzle, it would form a richer mixture implying lower flame base upstream propagation speed. Consequently the flame is stabilized further downstream for this nozzle. In contrast, the fuel injection rate and total fuel injected are the lowest for the conical nozzle, and, consequently, the liftoff length is smallest for this nozzle. Results in Fig. 12 and Table 4 further indicate that for all three nozzles, the liftoff length is smaller than the liquid length implying strong coupling between fuel vaporization and combustion processes under conditions investigated.

As stated earlier, diesel engine combustion involves a dual burning mode with a rich premixed flame near the stabilization region and a diffusion flame around the jet periphery. This combustion mode is well described by the Dec's “conceptual model” [15], based on laser-sheet imaging and optical data, as illustrated in Figure 13(a). In order to spatially resolve this lifted flame structure containing the rich premixed (RPZ) and non-premixed (diffusion) (NPZ) reaction zones, we developed a post-processing tool, based on a flame index [2,26], using data from 3D unsteady simulations. This flame index is defined as:

$$
\xi_{p}=\frac{1}{2}\left(1+\frac{G_{{\mathrm{CO} . \mathrm{O}_{2}}}}{\left|G_{{\mathrm{CO} . \mathrm{O}_{2}} \mid}\right|}\right) \quad \text { with } \quad G_{{\mathrm{CO} . \mathrm{O}_{2}}}=\nabla Y_{\mathrm{CO}} \cdot \nabla Y_{\mathrm{O}_{2}}
$$

where $\mathrm{Y}_{\mathrm{CO}}$ and $\mathrm{Y}_{\mathrm{O} 2}$ denote the $\mathrm{CO}$ and $\mathrm{O}_{2}$ mass fractions, respectively. The two reaction zones are resolved as:

$$
\begin{aligned}
& \xi_{p}=0 \Rightarrow \text { Rich Premixed Reaction Zone } \\
& \xi_{p}=1 \Rightarrow \text { Non-Premixed Reaction Zone }
\end{aligned}
$$

Note that conventional definition of flame index [36], based on fuel and oxidizer mass fractions, would not resolve the NPZ in the present case, since the fuel is completely consumed in the RPZ to form $\mathrm{CO}, \mathrm{H}_{2}$, and intermediate hydrocarbons. Consequently, we replaced fuel by $\mathrm{CO}$ in defining the flame index, since most of CO is produced in RPZ and consumed in NPZ. 
As shown in Fig. 13, the modified flame index is able to resolve the dual flame structure well, and reproduce the Dec's model for all three nozzles. There are, however, differences in the flame structures for the three nozzles. For the conical nozzle, the relative role of premixed combustion is enhanced (indicated by a longer RPZ) and that of diffusion combustion reduced (indicated by a shorter NPZ) compared to the other two nozzles. On the other hand, for the hydroground nozzle, the role of RPZ is reduced and that of NPZ enhanced compared to the other two nozzles. This has consequences for soot and NOx emissions, since most of soot is generated in RPZ, while NOx production mainly occurs in NPZ. Thus the amount of soot produced is expected to be the highest for the conical nozzle, and the NOx generation is expected to be highest for the hydroground nozzle. This is confirmed in Fig. 14, which presents the volumeaveraged soot and NOx and soot concentrations versus time for the three nozzles. The values are normalized using the maximum soot and NOx values. Results indicate the classical tradeoff between NOx and soot concentrations, with the conical nozzle producing highest soot but lowest NOx concentrations, while the hydroground nozzle producing lowest soot but highest NOx. The results are also consistent with experimental studies [13], indicating that the soot levels are inversely correlated to the flame liftoff lengths (cf. Fig. 12). This inverse correlation is consistent with experimental measurements by Pickett et al. [34] for non-oxygenated fuels. It is also interesting to note that the influence of nozzle geometry is more pronounced on soot emissions than on NOx emissions. Based on the NOx and soot tradeoff, a hydroground nozzle is more efficient in reducing overall emissions compared to a conical nozzle.

\section{CONCLUSIONS}

A recently developed primary breakup model (KH-ACT), which accounts for the effects of cavitation and turbulence generated inside the injector nozzle, has been incorporated into a CFD software CONVERGE for comprehensive engine simulations. The effects of nozzle orifice geometry (i.e., conicity and hydrogrinding) on spray and combustion processes have been examined by coupling the injector flow and spray simulations.

Conicity and hydrogrinding significantly reduce cavitation and turbulence levels inside the nozzle orifice, which slows down primary breakup, leading to larger droplets, increased spray penetration, and smaller dispersion. Consequently, with conical and hydroground nozzles, the vaporization rate and fuel air mixing are reduced, and ignition occurs further downstream. The flame structure and stabilization are also noticeably influenced by orifice geometry. The flame 
liftoff lengths are the highest and lowest for the hydroground and conical nozzles, respectively. This is mainly related to the rate of fuel injection, which is higher for the hydroground nozzle, leading to richer mixtures and lower flame base speeds for this nozzle.

Flame stabilization under diesel engine conditions seems to occur through a flame propagation mechanism, rather than an ignition kernel based mechanism observed by Pickett et al. [21]. A modified flame index is employed to resolve the lifted flame structure, which indicates a dual combustion mode under diesel engine conditions. For the conical nozzle, the relative role of rich premixed combustion is enhanced and that of diffusion combustion reduced compared to other two nozzles. In contrast, for the hydroground nozzle, the role of RPZ is reduced and that of NPZ is enhanced. Consequently, the amount of soot produced is highest with a conical nozzle, while the amount of NOx produced is the highest with a hydroground nozzle, indicating the classical tradeoff between NOx and soot emissions.

\section{ACKNOWLEDGMENTS}

This work is supported by the U.S. Department of Energy Office of Vehicle Technology under the management of Gurpreet Singh.

\section{REFERENCES}

1. Mulemane A, Han JS, Lu PH, Yoon SJ, Lai MC. Modeling dynamic behavior of diesel fuel injection systems. SAE Paper No. 2004-01-0536, 2004.

2. Som S. Development and validation of spray models for investigating Diesel engine combustion and emissions. PhD thesis, University of Illinois at Chicago; 2009.

3. Som S, Aggarwal SK, El-Hannouny EM, Longman DE. Investigation of nozzle flow and cavitation characteristics in a diesel injector. Journal of Engineering for Gas Turbine and Power 2010;132:1-12.

4. Payri F, Margot X, Patouna S, Ravet F, Funk M. A CFD study of the effect of the needle movement on the cavitation pattern of diesel injectors. SAE Paper No. 2009-24-0025; 2009.

5. Payri F, Bermudez V, Payri R, Salvador FJ. The influence of cavitation on the internal flow and the spray characteristics in diesel injection nozzles. Fuel 2004;83:419-431. 
6. Payri R, Salvador FJ, Gimeno J, Zapata LD. Diesel nozzle geometry influence on spray liquid-phase fuel penetration in evaporative conditions. Fuel 2008;87:1165-1176.

7. Bae C, Yu J, Kang J, Kong J, Lee KO. Effect of nozzle geometry on the common-rail diesel spray. SAE Paper No. 2002-01-1625; 2002.

8. Blessing M, Konig G, Kruger C, Michels U, Schwarz V. Analysis of flow and cavitation phenomena in diesel injection nozzles and its effects on spray and mixture formation. SAE Paper No. 2003-01-1358; 2003.

9. Benajes J, Pastor JV, Payri R, Plazas AH. Analysis of the influence of diesel nozzle geometry in the injection rate characteristics. Journal of Fluids Engineering 2004;126:6371.

10. Payri R, Garcia JM, Salvador FJ, Gimeno J. Using spray momentum flux measurements to understand the influence of diesel nozzle geometry on spray characteristics. Fuel 2005;84:551-561.

11. Han JS, Lu PH, Xie XB, Lai MC, Henein NA. Investigation of diesel spray primary breakup and development for different nozzle geometries. SAE Paper No. 2002-01-2775; 2002.

12. Som S, Aggarwal SK. An Assessment of Atomization Models for Diesel Engine Simulations. Atomization and Sprays 2009;19(9):885-903.

13. Hountalas DT, Zannis TC, Mavropoulos GC, Schwarz V, Benajes J, Gonzalez CA. Use of a Multi-Zone Combustion Model to Interpret the effet of injector nozzle hole geometry on HD DI Diesel Engine performance and pollutant emissions. SAE Paper No. 2005-01-0367; 2005.

14. Som S, Ramirez AI, Aggarwal SK, Kastengren AL, El-Hannouny EM, Longman DE, Powell CF, Senecal PK. Development and Validation of a Primary Breakup Model for Diesel Engine Applications. SAE Paper No. 2009-01-0838; 2009.

15. Dec JE. A conceptual model of DI Diesel Combustion Based on Laser-sheet Imaging. SAE Paper No. 970873; 1997.

16. Siebers DL, Higgins BS. Flame Lift-off on Direct-Injection Diesel Sprays under Quiescent Conditions. SAE Paper No. 2001-01-0530; 2001. 
17. Higgins BS, Siebers DE. Measurement of the Flame Lift-off Location on DI Diesel Sprays Using OH Chemiluminescence. SAE Paper No. 2001-01-0918; 2001.

18. Siebers DL, Higgins BS. Effects of injector conditions on the flame lift-off length of DI Diesel Sprays. Thermalfluidynamics Processes in Diesel Engines, Spain; 2000.

19. Peters N. Turbulent Combustion. Cambridge University Press; 2000.

20. Pickett LM, Siebers DL. An investigation of diesel soot formation processes using microorifices. Proceedings of the Combustion Institute 2002;29:655-662.

21. Pickett LM, Kook S, Persson H, Andersson O. Diesel fuel jet lift-off stabilization in the presence of laser-induced plasma ignition. Proceedings of the Combustion Institute 2009;32:2793-2800.

22. Ramirez AI, Som S, Aggarwal SK, Kastengren AL, El-Hannouny EM, Longman DE, Powell CF. Quantitative X-ray measurement of high-pressure fuel sprays from a production heavy duty diesel injector. Experiments in Fluids 2009;47:119-134.

23. Senecal PK, Pomraning E, Richards KJ. Multi-Dimensional Modeling of Direct-Injection Diesel Spray Liquid Length and Flame Lift-off Length using CFD and Parallel Detailed Chemistry. SAE Paper No. 2003-01-0243; 2003.

24. Richards KJ, Senecal PK, Pomraning E. CONVERGE ${ }^{\mathrm{TM}}$ (Version 1.2) Manual, Convergent Science Inc., Middleton, WI; 2008.

25. Senecal PK, Richards KJ, Pomraning E, Yang T, Dai MZ, McDavid RM, Patterson MA, Hou S, Sethaji T. A new parallel cut-cell Cartesian CFD code for rapid grid generation applied to in-cylinder diesel engine simulations. SAE Paper No. 2007-01-0159; 2007.

26. Som S, Aggarwal SK. Effect of primary breakup modeling on spray and combustion characteristics of compression ignition engines. Combustion and Flame 2010;157:11791193.

27. Reitz RD. Modeling Atomization Processes in High Pressure Vaporizing Sprays Atomization and Spray Technology 1987;3:309-337.

28. http://www.tfd.chalmers.se/ valeri/MECH.html.

29. Som S, Aggarwal SK. Modeling Diesel spray flame liftoff using detailed chemistry and a new primary breakup model. AIAA-2009-066;2009. 
30. Gauthier BM, Davidson DF, Hanson RK. Shock tube determination of ignition delay times in full-blend and surrogate fuel mixtures. Combustion and Flame 2004;139:300-311.

31. Kee RJ, Rupley FM, Miller J.A. A Fortran Chemical Kinetics Package for the Analysis of Gas Phase Chemical Kinetics. Technical Report SAND89-8009B, Sandia National Laboratories; 1993.

32. Sivaramakrishnan R, Som S, Brezinsky K, Aggarwal S.K. Validation of a Detailed Chemical Kinetic Modeling for the High Pressure Combustion of Methane- Flame and Ignition Characteristics. 5th US Combustion Meeting WSSCI; 2007.

33. Naber JD, Siebers D.L. Effects of gas density and vaporization on penetration and dispersion of diesel sprays. SAE Paper No. 960034; 1996.

34. Pickett LM, Siebers DL. Soot in diesel fuel jets: effects of ambient temperature, ambient density, and injection pressure. Combustion Flame 2004;138:114-135.

35. Siebers DE. Liquid-phase fuel penetration in diesel sprays. SAE Paper No. 980809; 1998.

36. Yamashita H, Shimada M, Takeno T. A numerical study on flame stability at the transition point of jet diffusion flames. Proceedings of the Combustion Institute 1996;26:27-34. 


\section{LIST OF FIGURES}

Figure 1: (a) Schematic of 6-hole full-production mini-sac nozzle. Only two holes are seen in this cross-sectional slice. Nozzle and needle region are identified along with the computational zone used in simulations. (b) Orifice geometry details are also presented.

Figure 2: Comparison of CHEMKIN simulations vs. experimental data of Gauthier et al. [21] for ignition delay times as a function of temperature for n-heptane/air mixtures.

Figure 3: Comparison of experimental flame lift-off image from Siebers and Higgins and flame lift-off [8] determined from $\mathrm{OH}$ mole-fraction and temperature contours.

Figure 4: Comparison of the KH-ACT model with images obtained from Siebers and Higgins at different (a) Orifice diameters, and (b) Injection pressures.

Figure 5: Validation of the KH-ACT model against liquid length and lift-off length data for various (a) orifice diameters, (b) pressure drop across injector orifice, at an ambient gas density and temperature of $14.8 \mathrm{~kg} / \mathrm{m}^{3}$, and $1000 \mathrm{~K}$ respectively.

Figure 6: Time sequence of PLII images [19] and predicted soot mass fraction contours (right). The dashed and solid vertical lines indicate the liftoff length and an axial location of $50 \mathrm{~mm}$, respectively.

Figure 7: Vapor volume fraction contours for the three orifices.

Figure 8: Discharge coefficient and injection velocity as a function of pressure drop across the orifice for the three orifices described in the context of Figs. 1 and 7.

Figure 9: Rate of injection profile for the (a) fuel injected vs. time, and (b) turbulent kinetic energy and area coefficient vs. time, for the three injector orifices described in the context of Figs. 1 and 7. The dashed vertical lines represent the needle lift positions.

Figure 10: Liquid penetration versus time (a) and transverse mass density profiles (b) at fixed axial locations for the three nozzles.

Figure 11: Spray penetration and flame development (in terms of temperature contours) for the three nozzles. Liquid length is indicated by a dashed line.

Figure 12: Effect of nozzle geometry on spray penetration, liquid length, and liftoff length. 
Figure 13: Effect of nozzle geometry on the flame structure depicted in terms of the RPZ and NPZ.

Figure 14: Normalized NOx and soot concentrations vs. time for the three nozzle orifices. 

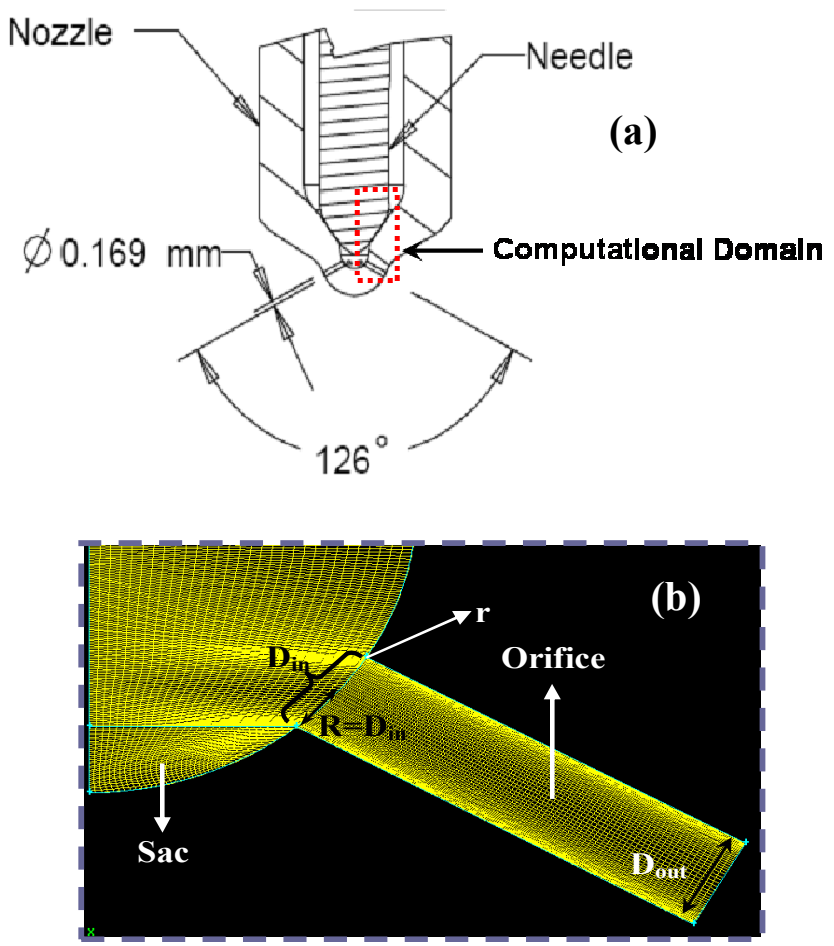

Figure 1 


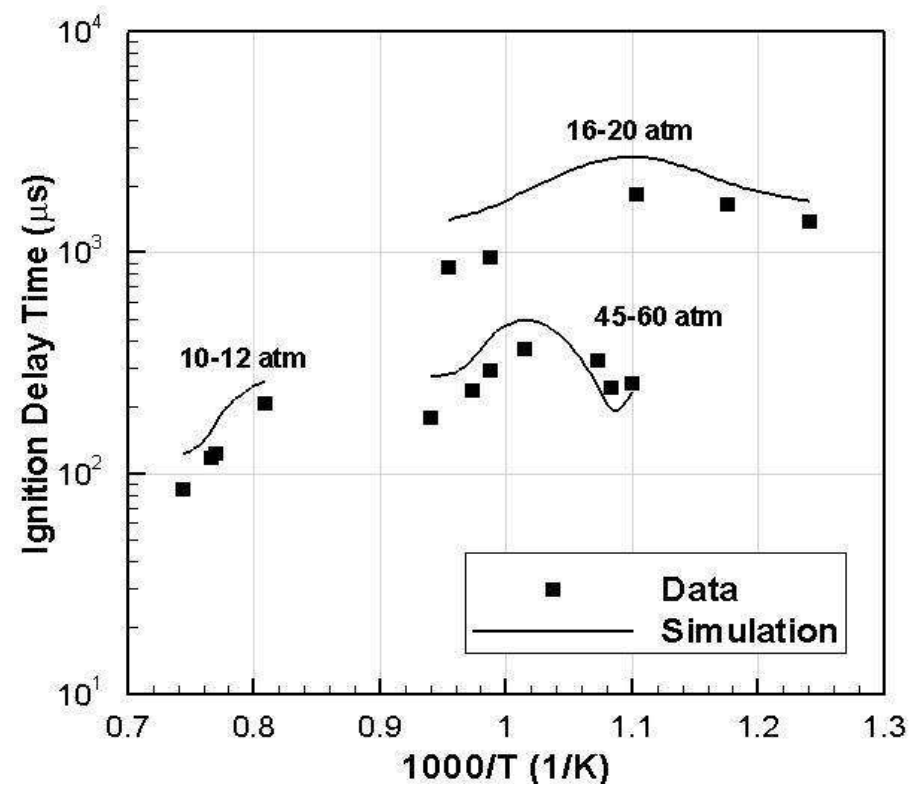

Figure 2 


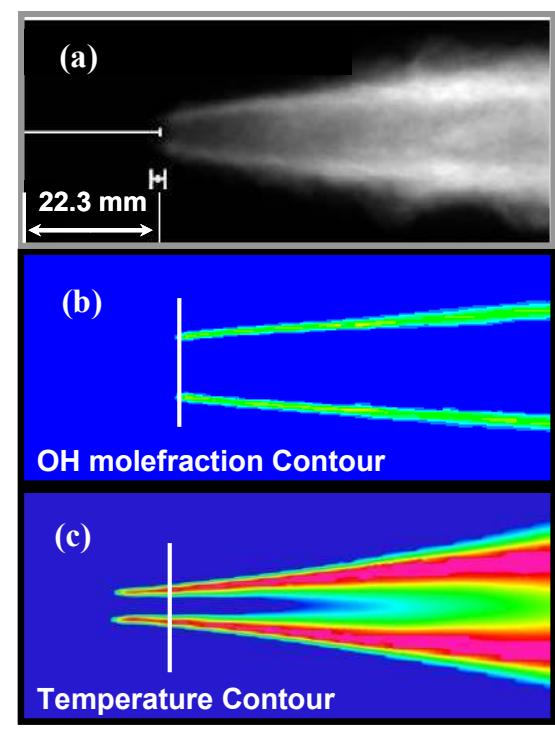

Figure 3 

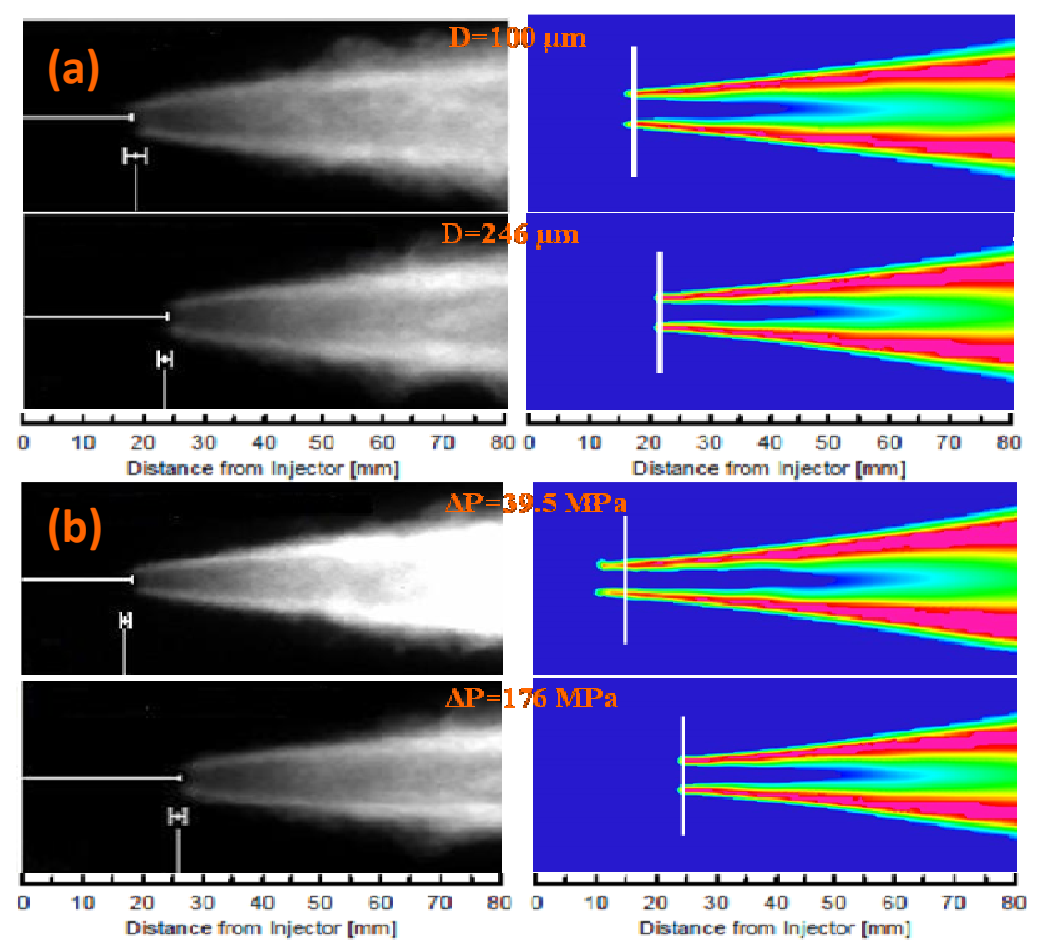

Figure 4 

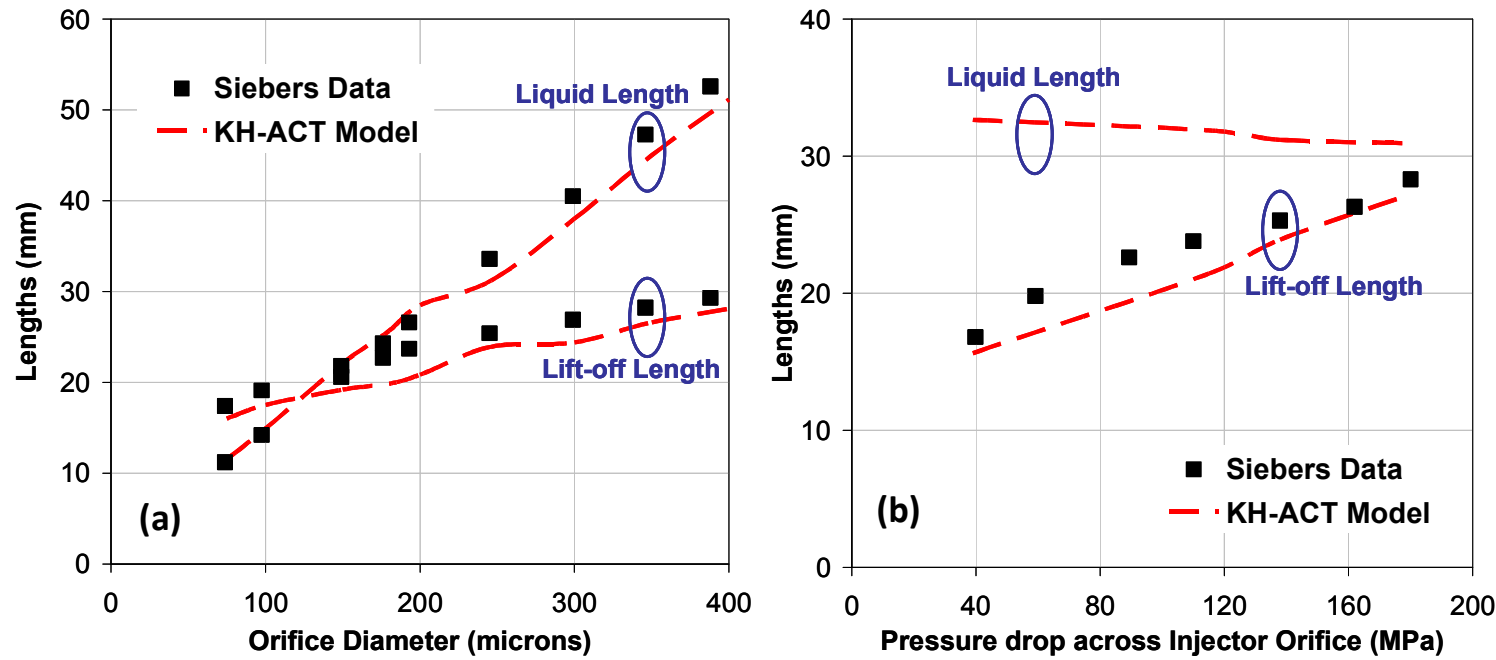

Figure 5 


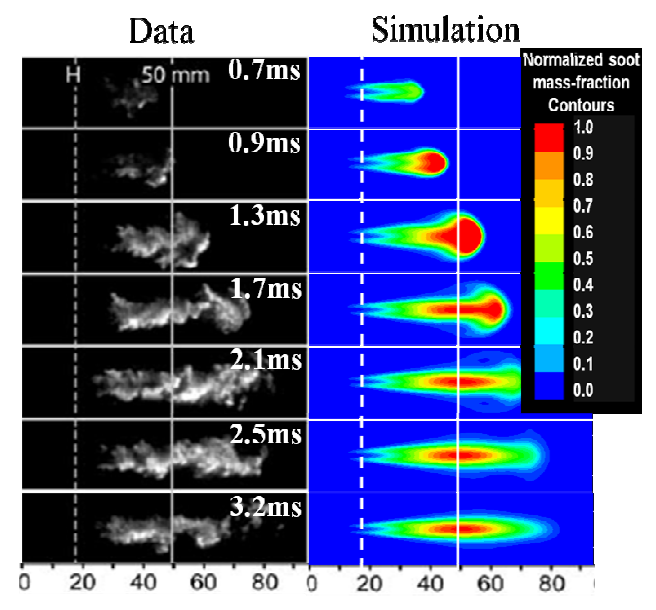

Figure 6 


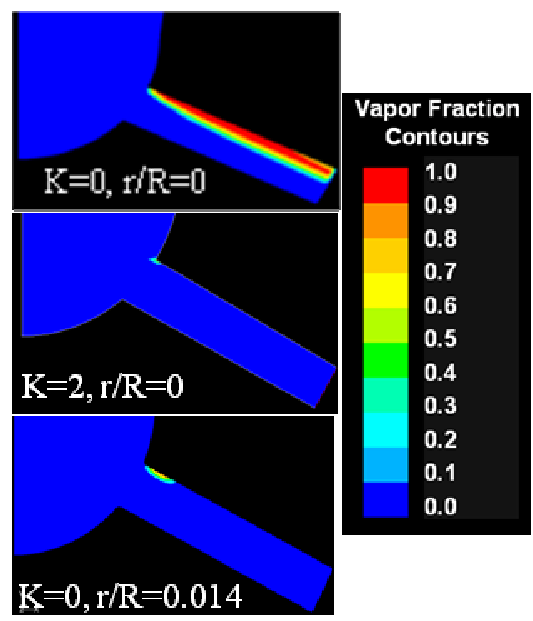

Figure 7 


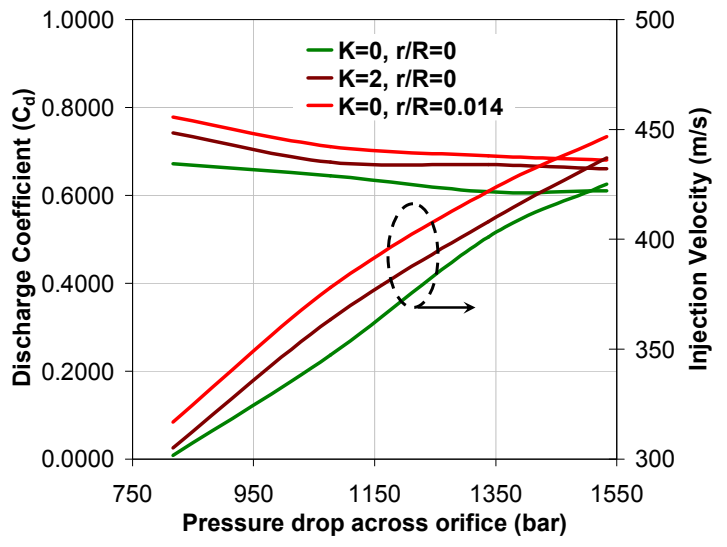

Figure 8 

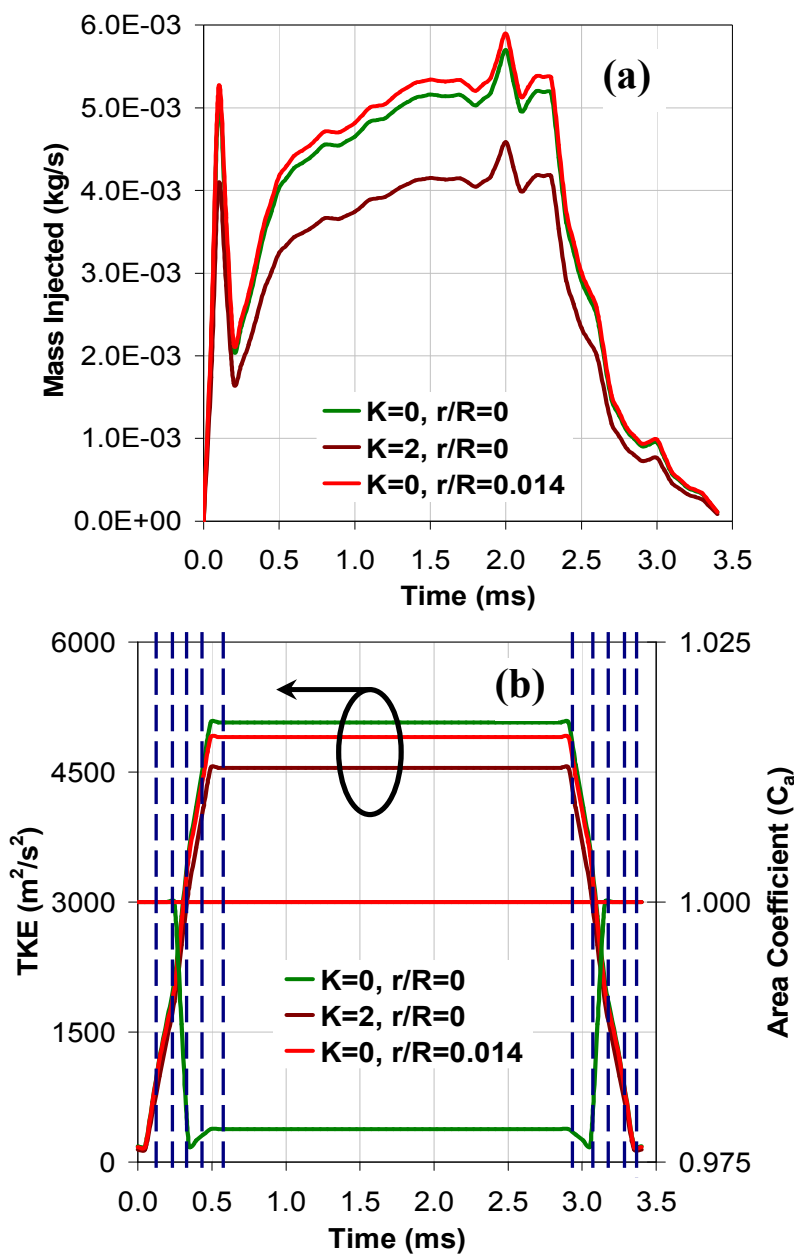

Figure 9 

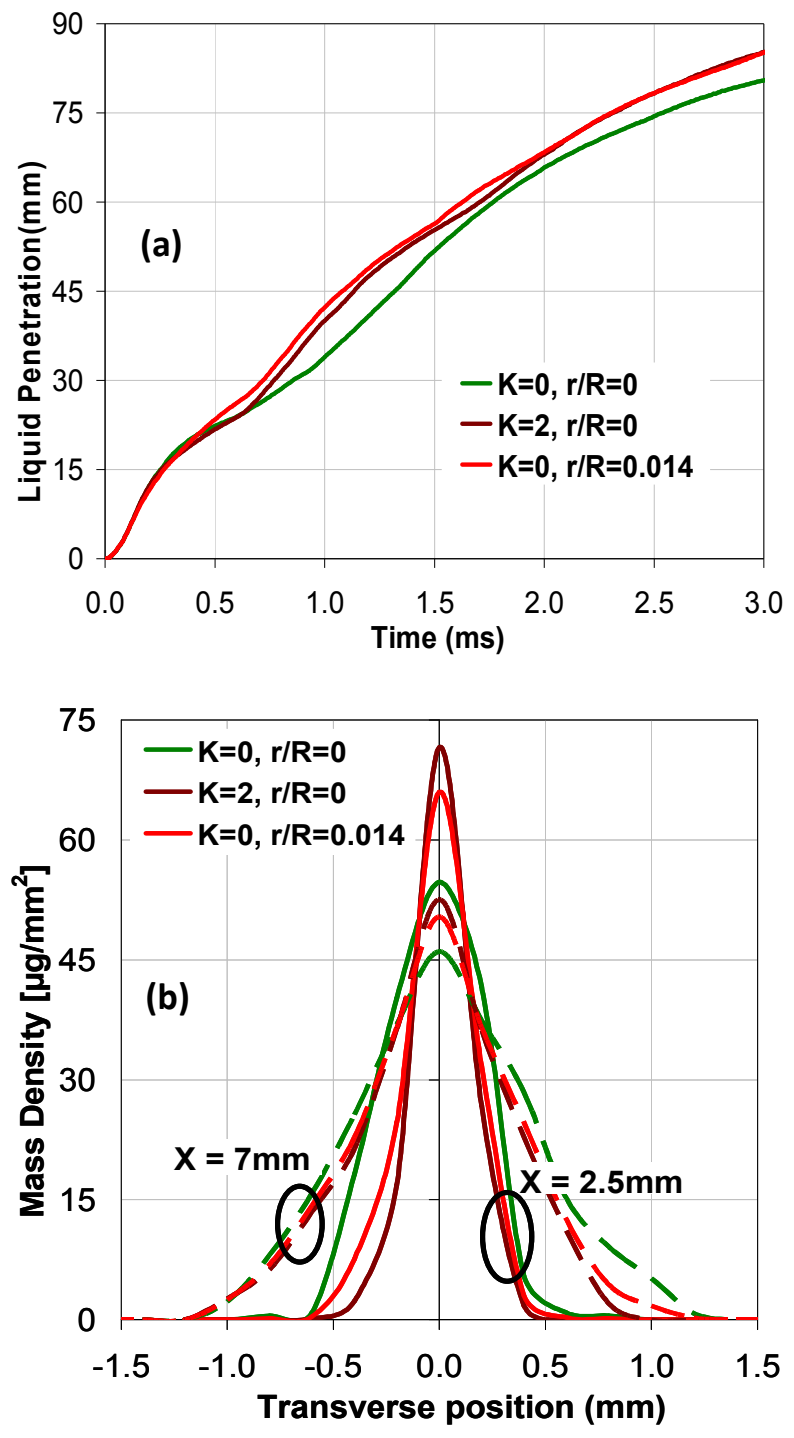

Figure 10 


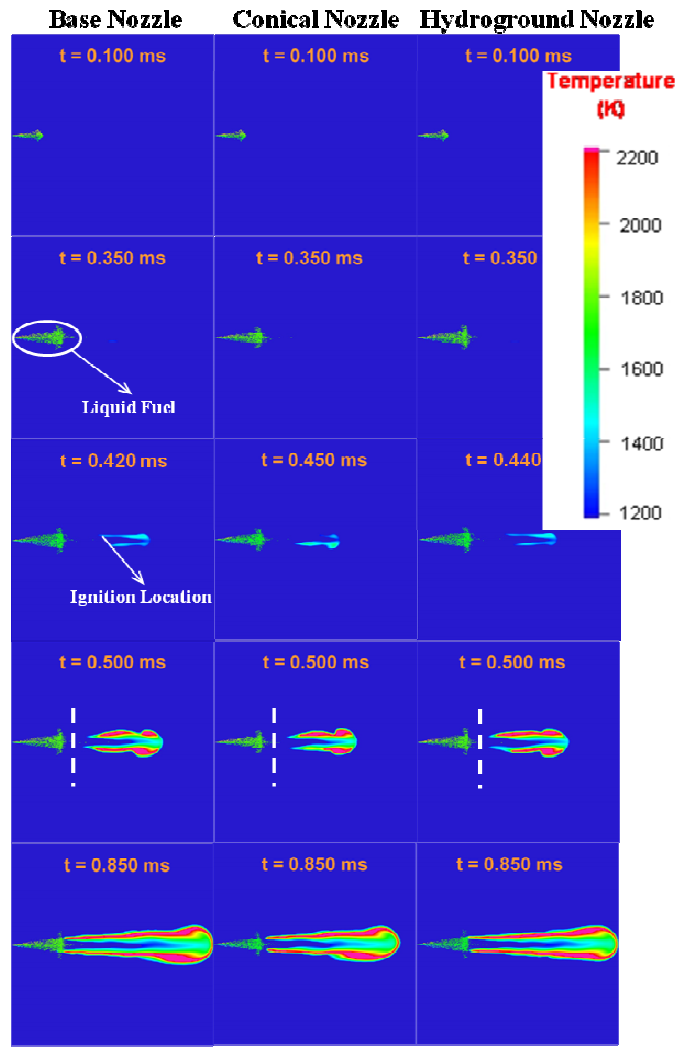

Figure 11 


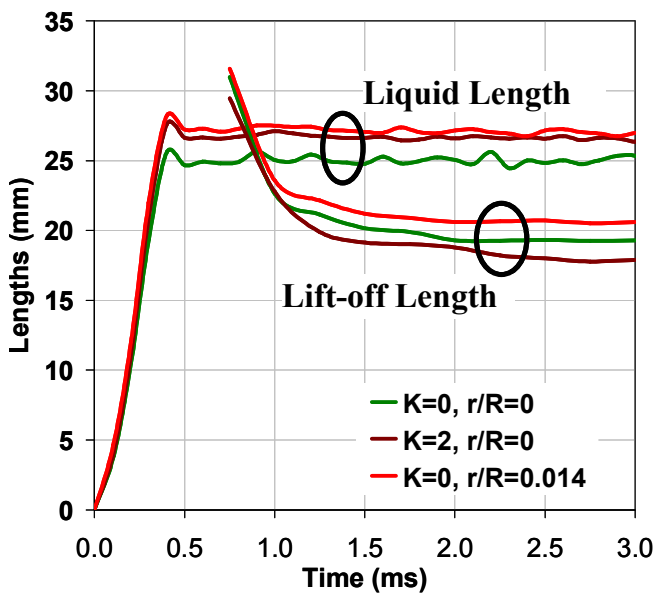

Figure 12 


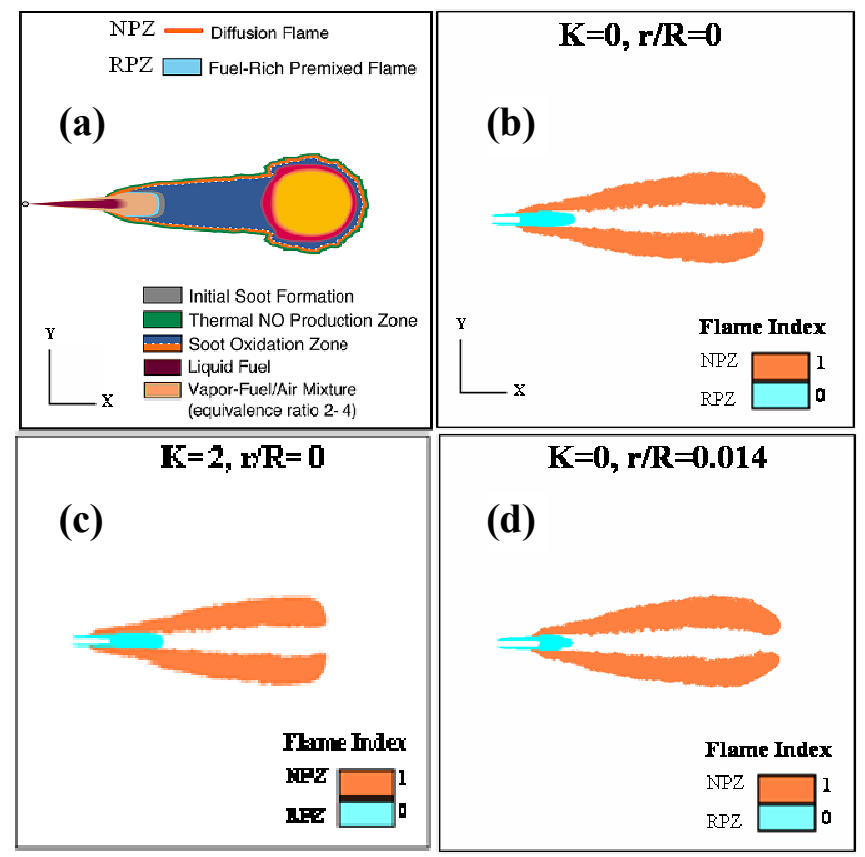

Figure 13 


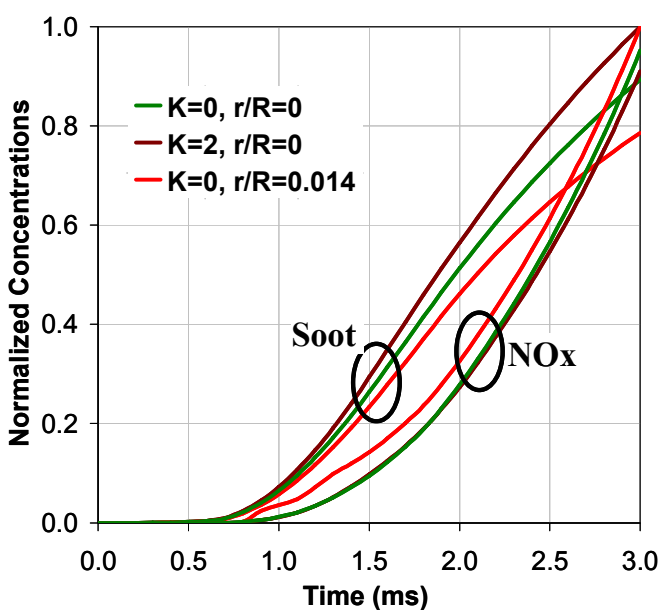

Figure 14 


\section{LIST OF TABLES}

Table 1: Geometrical characteristics of the nozzles simulated

Table 2: $\quad$ Simulated base conditions for the combusting spray experiments performed at Sandia National Laboratory.

Table 3: $\quad$ Influence of orifice geometry on inner nozzle flow and injection characteristics.

Table 4: $\quad$ Ignition time and location, liquid length, and flame liftoff length for the three nozzles. 


\begin{tabular}{|c|c|c|c|}
\hline $\begin{array}{c}\text { Geometrical } \\
\text { Characteristics }\end{array}$ & $\begin{array}{c}\text { Base } \\
\text { Nozzle }\end{array}$ & $\begin{array}{c}\text { Conical } \\
\text { Nozzle }\end{array}$ & $\begin{array}{c}\text { Hydroground } \\
\text { Nozzle }\end{array}$ \\
\hline $\mathbf{D}_{\text {in }}(\boldsymbol{\mu m})$ & 169 & 169 & 169 \\
\hline $\mathbf{D}_{\text {out }}(\boldsymbol{\mu m})$ & 169 & 149 & 169 \\
\hline $\mathbf{K}_{\text {factor }}$ & 0 & 2 & 0 \\
\hline $\mathbf{r} / \mathbf{R}$ & 0 & 0 & 0.014 \\
\hline $\mathbf{L} / \mathbf{D}$ & 4.2 & 4.7 & 4.2 \\
\hline
\end{tabular}

Table 1 


\begin{tabular}{|c|c|}
\hline Orifice Diameter & $246 \mu \mathrm{m}, \mathrm{L} / \mathrm{D}=4.2$ \\
\hline Injection Pressure [bar] & 1400 \\
\hline Fill Gas & $\begin{array}{c}\text { Mixture of } \mathrm{N}_{2}=0.693, \mathrm{O}_{2}=0.21, \\
\mathrm{CO}_{2}=0.061, \mathrm{H}_{2} \mathrm{O}=0.036\end{array}$ \\
\hline Chamber Density $\left[\mathbf{k g} / \mathbf{m}^{\mathbf{3}}\right]$ & 14.8 \\
\hline Chamber Temperature $[\mathbf{K}]$ & 1000 \\
\hline
\end{tabular}

Table 2 


\begin{tabular}{|c|c|c|c|c|}
\hline \multirow{5}{*}{$\begin{array}{c}\text { Nozzle } \\
\text { Flow } \\
\text { Character- } \\
\text { istics }\end{array}$} & Parameters & $\begin{array}{c}\text { Base } \\
\text { Nozzle }\end{array}$ & $\begin{array}{l}\text { Conical } \\
\text { Nozzle }\end{array}$ & $\begin{array}{l}\text { Hydroground } \\
\text { Nozzle }\end{array}$ \\
\hline & Exit Area & --- & $\rrbracket$ & --- \\
\hline & Exit Density & --- & $\widehat{\mathbb{1}}$ & $\hat{1}$ \\
\hline & Exit Velocity & --- & $\widehat{\imath}$ & $\hat{1}$ \\
\hline & $\begin{array}{l}\text { Discharge } \\
\text { Coefficient }\end{array}$ & --- & $\Uparrow$ & $\Uparrow$ \\
\hline \multirow{4}{*}{$\begin{array}{c}\text { Injection } \\
\text { Character- } \\
\text { istics }\end{array}$} & $\begin{array}{c}\text { Area } \\
\text { Coefficient }\end{array}$ & $\Downarrow$ & --- & --- \\
\hline & Injection rate & --- & $\downarrow$ & $\hat{\mathbb{1}}$ \\
\hline & TKE $\left(\mathrm{m}^{2} / \mathrm{s}^{2}\right)$ & --- & $\downarrow$ & $\downarrow$ \\
\hline & $\operatorname{TDR}\left(\mathrm{m}^{2} / \mathrm{s}^{3}\right)$ & --- & $\downarrow$ & $\downarrow$ \\
\hline
\end{tabular}

Table 3 


\begin{tabular}{|c|c|c|c|c|}
\hline Nozzle type & $\begin{array}{c}\text { Ignition } \\
\text { time } \\
(\mathbf{m s})\end{array}$ & $\begin{array}{c}\text { Ignition } \\
\text { location } \\
(\mathbf{m m})\end{array}$ & $\begin{array}{c}\text { Liquid } \\
\text { length } \\
(\mathbf{m m})\end{array}$ & $\begin{array}{c}\text { Liftoff } \\
\text { length } \\
\text { (mm) }\end{array}$ \\
\hline $\begin{array}{c}\text { Base } \\
(\mathrm{K}=0, \mathrm{r} / \mathrm{R}=0)\end{array}$ & 0.42 & 47.2 & 25.1 & 19.3 \\
\hline $\begin{array}{c}\text { Conical } \\
(\mathrm{K}=2, \mathrm{r} / \mathrm{R}=0)\end{array}$ & 0.44 & 48.8 & 26.9 & 17.9 \\
\hline $\begin{array}{c}\text { Hydroground } \\
(\mathrm{K}=0, \mathrm{r} / \mathrm{R}=0.014)\end{array}$ & 0.45 & 49.2 & 27.2 & 20.6 \\
\hline
\end{tabular}

Table 4 